\title{
A matemática na formação dos professores do ensino primário em Portugal, da reforma pombalina de 1772 até 1910
}

\author{
Rui Candeias* \\ José Manuel Matos**
}

\section{Resumo}

As escolas de formação de professores para os anos elementares desempenharam um papel central na formação do saber pedagógico em Portugal. Sendo assim, este artigo pretende contribuir para o conhecimento dos saberes matemáticos e do seu ensino desenvolvidos nestas escolas até 1910. Este estudo histórico documental baseou-se na legislação (leis, decretos, portarias, circulares e instruções enviadas às escolas). No texto, após uma breve caraterização da evolução das escolas normais, estudase a presença da matemática sucessivamente: nos exames de acesso à profissão para os candidatos sem o curso das escolas normais; nos exames de acesso às escolas normais; nas disciplinas destas escolas; e nos conteúdos das disciplinas agrupados consoante os tópicos matemáticos. Quanto aos conteúdos matemáticos, dois eixos se tornaram claros. Se por um lado eles foram tornando mais complexos (incluindo, por exemplo, a álgebra ou os logaritmos), por outro desde muito cedo a matemática estudada envolve temas próximos de aplicações profissionais (contabilidade, agrimensura) e que fazem parte da função formativa das escolas primárias portuguesas no período em análise. $\mathrm{O}$ estudo destes programas mostra a construção gradual de um conjunto de saberes matemáticos, que vão para além do que o futuro professor teria que ensinar, onde são também apresentadas algumas sugestões de caráter metodológico, em linha com o que seria de esperar da gradual construção de uma cultura de escola de formação de professores do ensino primário.

Palavras-chave: História Geral da Educação. Formação dos Profissionais da Educação. Ensino de Matemática.

\footnotetext{
* Professor do Agrupamento de Escolas Terras de Larus/Unidade de Investigação Educação e Desenvolvimento, Faculdade de Ciências e Tecnologia da Universidade Nova de Lisboa.

*** Professor Aposentado da Faculdade de Ciências e Tecnologia da Universidade Nova de Lisboa.
} 
As escolas de formação de professores para os anos elementares, Escolas Normais, desempenharam um papel central na formação do saber pedagógico em Portugal e contribuíram para a constituição do que hoje denominamos de Ciências da Educação. A investigação histórica tem-se debruçado detalhadamente sobre elas e as propostas conceptuais de Chervel (1990), valorizando a autonomia das disciplinas escolares, revelaram-se produtivas, em particular quanto ao estudo das representações associadas às disciplinas denominadas Pedagogia ou Didática ${ }^{1}$ o que permitiu mapear o desenvolvimento inicial do pensamento pedagógico em Portugal (PINTASSILGO, 2012). Foi nessas escolas que os primeiros manuais destinados a professores foram escritos e estudados e foi nelas que as tendências da Escola Nova foram apropriadas e transformadas em alternativas pedagógicas centradas nos alunos.

No entanto, se o ensino das matemáticas elementares em Portugal já foi tema de investigação histórica que os textos de Matos (2007) e Almeida e Candeias (2014) sintetizam, o ensino e a aprendizagem da matemática nas Escolas Normais não foi ainda objeto de estudo. A finalidade deste trabalho é, pois, contribuir para o conhecimento dos saberes matemáticos, e do seu ensino, desenvolvidos nessas escolas. Analisámos em particular os conteúdos relacionados com a matemática, e o seu ensino, nas peças legislativas dedicadas às escolas de formação de professores para o ensino primário em Portugal desde a reforma pombalina de 1772 até à implantação da república, em 1910. Numa primeira parte traçámos um breve quadro da implementação das escolas de formação de professores do ensino primário em Portugal. Focámo-nos depois especificamente nos conteúdos matemáticos, onde analisámos primeiramente os tópicos dos exames de acesso à profissão. A partir de 1860 as escolas normais foram assumindo importância e, sempre focados na matemática e no seu ensino, estudámos sucessivamente as provas de acesso a essas escolas, a estrutura curricular e os programas das disciplinas com conteúdos relacionados com a matemática.

A elaboração deste trabalho foi guiada pelo levantamento já efetuado em Almeida e Candeias (2014). Analisámos a legislação que, para além dos normativos habituais (leis, decretos e portarias), incluiu também circulares e instruções enviadas às escolas e nesses materiais procurámos as referências à matemática e ao seu ensino. A cultura escolar, nos termos propostos por Julia (1995), distingue entre as representações (as normas) e as práticas. Sendo assim, este trabalho incidiu sobre as primeiras. Para operacionalizar a análise, conduzimos um estudo histórico documental (MCCULLOCH, 2004).

Uma primeira revisão dos materiais fez ressaltar algumas categorias, que forneceram a estrutura a este texto: os exames de provimento nas cadeiras de instrução primária quando o diploma da escola 
normal não era obrigatório, os conteúdos dos exames de admissão às escolas de formação de professores, as suas disciplinas e os respetivos planos de estudos. Para a análise dos programas foram ainda criadas categorias relacionadas aos diversos temas da disciplina de matemática.

\section{As escolas de formação de professores do ensino primário}

A segunda metade do século XVIII foi um momento marcante para o início da constituição da profissão docente do ensino não superior em Portugal. Ainda no quadro de um regime absolutista centrado no poder real, a reforma pombalina de 1772 regulamentou pela primeira vez a profissionalização dos mestres de ler, escrever e contar. Os critérios de admissão, as regras para a certificação profissional, o exercício da profissão e a sua remuneração saíram da alçada da Igreja e passaram a ser tutelados pelo Estado. Ao tornar-se um funcionário do Estado, o professor passou a estar sujeito às suas normas, nomeadamente no que diz respeito aos conteúdos a ensinar e aos métodos a utilizar para o seu ensino (NÓVOA, 2003; PINTASSILGO, 2012). A partir do final do século XVIII deixou de ser permitido ensinar sem uma licença ou autorização estatal, a qual era concedida mediante a realização de um exame que podia ser requerido por indivíduos que reunissem certas condições, como habilitações, idade ou comportamento moral. Este exame contribuiu para delimitar o campo profissional, passando a caber aos professores o direito exclusivo de intervenção nesta área. No entanto, nessa fase ainda se estava muito longe da concretização de um sistema de formação de professores. A via de acesso à profissão através de exames de habilitação vigorará até 1901 .

Podemos estabelecer três períodos no lento desenvolvimento de escolas de formação de professores primários em Portugal. Um primeiro período decorreu de 1816 até 1860, onde se consolidou nos poderes públicos a ideia de que para ser professor era necessária uma formação relativamente longa, realizada em instituições criadas especificamente para o efeito. São desta época as primeiras tentativas de promover a formação de mestres, como são exemplos a Escola Normal para Habilitação dos mestres das escolas regimentais (1816-1818) e a Escola Normal de Ensino Mútuo ou Escola Normal de Lisboa, situada em Belém (1824-1835). São instituições criadas de forma casuística e sem um plano de âmbito nacional, mas que se vão manter até $1869^{2}$.

Apenas após a Revolução Liberal em 1820, e terminada a guerra civil do princípio dos anos 1830, apareceram os primeiros projetos de criação de escolas públicas para a formação de professores para as escolas primárias, de par com a criação de um embrião de um sistema de ensino secundário. 
Primeiro, em 1835 foi projetada a criação de duas escolas normais, em Lisboa e no Porto, e em 1836 foi planeada a construção de escolas de ensino mútuo em cada capital de região administrativa que funcionariam em simultâneo como escolas normais. Só algumas destas escolas chegaram a abrir e a sua atividade permaneceu irregular (GOMES, 1996; PINTASSILGO, 2012). A reforma de Costa Cabral (1844) propôs um sistema de formação de professores de instrução primária e legislou em 1845 sobre a Escola Normal Primária em Lisboa agregada à Casa Pia, mas que não entrou em funcionamento (PINTASSILGO; MOGARRO, 2015). A reforma de 1844 separou pela primeira vez o ensino primário em dois graus sequenciais (o $1^{\circ}$ e o $2^{\circ}$ graus) com os seus professores específicos. Essa distinção foi mantida durante vários anos, embora a denominação fosse, por vezes, alterada.

Um segundo período decorreu entre 1860 e 1901, acompanhando uma fase de desenvolvimento económico. A progressiva homogeneização da escola que ocorreu durante todo o século XIX em Portugal (BARROSO, 2005) e que formalizou o ensino secundário, conduziu igualmente à institucionalização da formação de professores primários. O início de uma formação estruturada de professores para o ensino primário em Portugal ocorreu com o Regulamento para a Escola Normal Primária do Distrito de Lisboa de 1860, a que se seguiu, em 1862, a entrada em funcionamento da Escola Normal Primária de Marvila, em Lisboa. Essa escola, em regime de internato apoiado pelo Estado, destinava-se à formação de professores do ensino primário do sexo masculino e foi a primeira escola normal oficial integrada num plano mais amplo de formação de professores para o ensino primário. Até 1869, a formação nessa escola dedicou atenção à agricultura e às atividades culturais: “A formação conferida pela escola visava um ensino verdadeiramente profissional, baseado na pedagogia e que aliava a dimensão teórica a uma aprendizagem puramente prática" (PINTASSILGO; MOGARRO; HENRIQUES, 2010, p. 13).

Uma escola normal para o sexo feminino foi regulamentada em 1863, mas só entrou em funcionamento, também em regime de internato, em 1866, num recolhimento situado no Calvário em Lisboa (PINTASSILGO, 2012).

No final da década de 1860 ocorreram tentativas para alargar o âmbito do ensino normal, que então se reduzia a Lisboa e a poucas escolas normais de ensino mútuo. Assim, no início de 1869 procurou-se associar o ensino normal a alguns liceus, criando nestes cadeiras de Pedagogia e com a consequente extinção da Escola de Lisboa. No final do mesmo ano optou-se por outro caminho, criando escolas normais em Lisboa, Porto, Coimbra, Évora e Viseu e extinguindo as escolas normais de 
ensino mútuo ainda existentes. Em 1870 foram criadas duas escolas normais femininas em Lisboa e Porto (GOMES, 1996).

A partir de meados da década de 1890 assistiu-se a um processo de diferenciação entre as escolas normais, instituindo-se escolas de habilitação para o magistério de professores do ensino primário nas capitais de distrito do país. Essas escolas ofereciam uma formação simplificada e com carácter regional, relativamente às escolas normais consideradas de referência (Lisboa, Porto e Coimbra) (PINTASSILGO, 2012). A partir de 1896, os candidatos a professores que não tivessem frequentado as escolas normais passavam a ter que fazer exames perante essas escolas, exames esses que tinham como referência os programas das Escolas Normais.

O terceiro período decorreu entre 1901 e 1910. O Decreto n. ${ }^{\circ} 8$, de 1901, estabeleceu que a habilitação para a prática do ensino primário passava a depender da aprovação obrigatória no curso das Escolas Normais ou das Escolas de Habilitação para o Magistério Primário e terminou com a possibilidade de pessoas sem esse curso poderem aceder à profissão (PORTUGAL, 1901). Em rigor, um passo intermédio importante no sentido da profissionalização docente tinha já sido dado com o Regulamento Geral do Ensino Primário de 1896, que definiu que os exames de habilitação para a docência passariam a ser feitos nas Escolas Normais (PORTUGAL, 1896). No final desse período, a implantação da República em Portugal mudou o contexto escolar, pelo que estabelecemos o ano de 1910 como referência para o final da análise que efetuámos à matemática nos programas de formação dos professores do ensino primário.

Em 1910, no final da Monarquia existiam seis escolas normais em Lisboa, Porto e Coimbra (uma para cada sexo em cada uma destas cidades) e 17 escolas de habilitação para o magistério primário, nas capitais de distrito, exceto Santarém. Essa rede de escolas era vista como um sobredimensionamento do sistema, já que se diplomavam mais professores do que era julgado necessário, muitos ficando desempregados ou exercendo atividades não relacionadas com a docência. Essa situação prolongar-se-ia até 1921, quando as escolas enquadradas na reforma de 1901 foram encerradas e substituídas pelas novas instituições republicanas (PINTASSILGO, 2012).

Apesar de se considerar que estavam a ser formados demasiados professores para o ensino primário, na realidade a percentagem de analfabetismo na população portuguesa da época era muito superior à de países europeus com um desenvolvimento económico similar. De acordo com Carvalho (1996), os números do analfabetismo constituíam uma calamidade e uma vergonha nacional, sendo analfabeta cerca de 82,4\% da população portuguesa em 1878 e $75 \%$ em 1911. Referindo-se aos dados 
de meados da década de 1860, Candeias (2005) salienta que a percentagem de crianças inscritas no ensino elementar também apresentava números muito inferiores, comparativamente com outros países europeus.

\section{Exames de acesso aos lugares de professor primário}

O estudo das normas que regulam os exames aos candidatos a professores primários, em particular as dimensões científicas, pedagógicas ou morais valorizadas, permite-nos conhecer as representações, no sentido de Julia (1995), que os poderes públicos faziam da profissão. Como vimos na secção anterior, até 1901 os cursos de escolas normais não eram obrigatórios para alcançar um lugar de professor do ensino primário público, pois o acesso podia ocorrer mediante um exame. Estes foram instituídos pela primeira vez pelo Marquês de Pombal em 1772 (GOMES, 1996) e mantiveram-se durante todo o século XIX. O Regulamento Geral da Instrução Primária de 1835 (PORTUGAL, 1835) estabeleceu as normas que deviam reger a contratação de professores primários para as escolas públicas, exigindo que para os lugares de ensino primário apenas fossem admitidas pessoas habilitadas com o curso da escola normal. No entanto, tratava-se apenas de um enunciado de intenções, pois tal só veio a acontecer a partir de 1901. A Reforma da Instrução Pública de 1844 (PORTUGAL, 1844), que veio a ser o normativo seguido durante muitos anos, optou antes pela possibilidade de realização de um exame. Estabelecia-se no artigo $18^{\circ}$ que:

[...] as cadeiras de Instrução Primária, assim do primeiro, como do segundo grau, serão providas por concurso e exames públicos, orais e por escrito que terão lugar nos respetivos Liceus, sobre todos os objetos, que, nas Escolas Normais, formarem concurso de habilitações para o respetivo grau. (PORTUGAL, 1844, p. 308).

Até 1870 , teriam sido estes os procedimentos seguidos. Tipicamente, o Governo publicitava os lugares a concurso e os candidatos apresentavam a documentação no Liceu. Um Relatório de 1869 (PORTUGAL, 1869) critica estes procedimentos:

[...] o sistema há longos anos adotado para o provimento das cadeiras de ensino primário [...] de abrir concursos parciais de todas as vezes que vaga uma cadeira, e de confiar os exames a júris de três membros, compostos pela maior parte de professores de instrução primária mais vizinhos do local desses exames, ou, na falta deles, a professores dos liceus, tem graves inconvenientes de sobejo demonstrados pela prática. (PORTUGAL, p. 512, grifo do autor). 
Nessas provas de exame, um diploma de Escola Normal era uma condição de preferência, mas menos relevante de que um do ensino superior ou do ensino secundário (PORTUGAL, 1844, §3, art. $^{\circ}$ $\left.18^{\circ}\right)$.

Em 1869 foi publicado o já citado Regulamento (PORTUGAL, 1869) para os exames dos concorrentes às cadeiras de ensino primário do $1^{\circ}$ e $2^{\circ}$ grau, seguido em 1870 por programas detalhados para estes exames (PORTUGAL, 1870). Contrariava-se a prática anterior, que deixava a escolha de grande parte do conteúdo dos exames nas mãos de júris locais. De acordo com o Regulamento, todos os anos existiam duas épocas destinadas à admissão a exames dos candidatos, uma em março e outra em outubro.

Segundo o Regulamento de 1869 (PORTUGAL, 1869), o júri era composto de cinco elementos nomeados entre professores de instrução primária, secundária ou superior e de outros funcionários públicos, ou indivíduos que tivessem habilitações científicas, que exercessem o magistério nos estabelecimentos de ensino livre. O comissário de estudos, ou os reitores dos liceus onde funcionava o júri, seriam membros do mesmo.

$\mathrm{Na}$ linha dos normativos anteriores, os pretendentes às cadeiras de instrução primária do $1^{\circ}$ e do $2^{\circ}$ grau deveriam apresentar ao júri a documentação necessária. Os candidatos poderiam acrescentar atestados de habilitações literárias ou científicas, que permitiam dar preferência no caso de igualdade de graduação. Depois os candidatos realizavam provas públicas. Os exames eram escritos e orais, por esta ordem, sendo comuns para todos os candidatos, e ocorrendo no mesmo dia e local. Os elementos do júri votariam o valor de cada uma das provas escritas, de acordo com um valor máximo designado nos programas para cada uma dessas provas. Os candidatos que não obtivessem no total das provas escritas um valor superior a um terço do valor máximo previsto para essas provas, eram excluídos das provas orais. Para os que ficassem aprovados para as provas orais, os valores obtidos nas provas escritas eram tomados em conta na graduação final.

Nas provas orais para os candidatos masculinos (e destinados a escolas masculinas), propostas em 1870, eram avaliados um conjunto de temas (designados por “disciplinas”), que incluíam a leitura, gramática, história sagrada, aritmética e sistema métrico, geografia, história, pedagogia, noções elementares de agricultura. Nas provas orais, os conteúdos de matemática eram avaliados em Aritmética e Sistema métrico decimal. As disciplinas com conteúdos de matemática representavam $12,5 \%$ da pontuação das provas orais. As provas escritas envolviam alguns dos temas anteriores e, 
quanto à matemática, a resolução de dois problemas aritméticos e o desenho linear geométrico. No total, os conteúdos relacionados com a matemática representavam aproximadamente $30 \%$ do total.

Destaca-se que, tanto nas provas orais como nas escritas, existia o exame da disciplina de Pedagogia onde eram abordados temas relacionados com o ensino de conteúdos matemáticos, que não se encontravam discriminados nos documentos legais.

Os exames das concorrentes às escolas do sexo feminino (destinadas a lugares em escolas femininas) eram também contemplados no Programa de 1870. Embora globalmente as provas para candidatos dos dois sexos partilhassem muitas semelhanças, distinguiam-se na simplificação de alguns requisitos das candidatas nas áreas de língua portuguesa, aritmética, história e geografia, agricultura e desenho linear. Essa simplificação era compensada pelas provas práticas de lavores e por uma maior valorização da pedagogia.

A prova de Aritmética estava dividida em três partes. A primeira incluía essencialmente os números inteiros, operações com números inteiros e respetivas provas e números decimais:

I - Quantidade, unidade e número; Número abstrato e concreto, inteiro, quebrado e misto; Artifício da numeração, numeração oral, escrita e romana; Modo de usar do contador mecânico para explicar a numeração às crianças; Operações da aritmética, adição, subtração, multiplicação e divisão de números inteiros; Emprego do contador para ensinar estas operações; Tirar os nove a um número; Provas reais e dos nove aplicadas às quatro operações; Numeração decimal; Regras e prática das quatro operações sobre os números decimais; Multiplicar ou dividir um número inteiro ou decimal por 10, 100, 1000, etc., só com auxílio da vírgula. (PORTUGAL, 1869, p. 409).

Na segunda parte, destinada apenas aos candidatos masculinos, estavam incluídos os critérios de divisibilidade, números fracionários e números decimais e as operações com fracionários:

II - Regras para conhecer quando um número é exatamente divisível por 2, 3, 4, 5, 9, 10; Quebrados, modo de os representar, modo de os simplificar, redução à dízima, aproximar um quociente em partes decimais, redução de dois ou mais quebrados ao mesmo denominador; Regras e prática das quatro operações sobre quebrados. (PORTUGAL, 1869, p. 409).

A terceira parte, também apenas para os candidatos masculinos, continha razões e proporções, resolução de problemas e regras de auxílio à resolução de problemas e cálculo comercial:

III - Razões e proporções; Razão aritmética, proporção aritmética, propriedade fundamental; Razão geométrica, proporção geométrica, propriedade fundamental; Aplicação da aritmética aos usos da vida; Regra de três simples, direta e inversa; Regra de três composta; Resolução de problemas pelas proporções e pelo método de redução 
à unidade; Regras de juros simples e composta; Descontos; Regras de companhia simples e composta. (PORTUGAL, 1869, p. 409).

Relativamente ao tema Sistema métrico decimal, os conteúdos examinados referiam-se às diferentes medidas do sistema métrico, às medidas agrárias, aos instrumentos de medida e seu conhecimento prático e ao sistema monetário.

Sistema métrico; Medidas de comprimento, metro, seus múltiplos e submúltiplos; Medidas de capacidade, litro, seus múltiplos e submúltiplos; Medidas agrárias, are, seu múltiplo e submúltiplo; Estere; Balança decimal; Conhecimento prático e uso destas medidas; Sistema legal e moedas. (PORTUGAL, 1869, p. 409).

No tema de Pedagogia, para além de aspetos mais gerais relacionados com a disciplina, comportamento e mobília escolar, eram também avaliados conteúdos relacionados ao Ensino do cálculo mental e da aritmética e Ensino do sistema métrico. Nesta disciplina eram ainda examinados os conhecimentos dos candidatos sobre os métodos de ensino, pedindo-se que fizessem uma exposição dos diversos métodos, designadamente o modo individual, mútuo, misto e simultâneo.

O Desenho Linear apresentava-se dividido em Desenho geométrico e Desenho à vista. Na primeira parte, apenas destinada aos homens, eram incluídos conteúdos relacionados com a matemática, como traçar duas retas paralelas, traçar um ângulo reto, agudo, obtuso ou de um determinado número de graus e avaliar as áreas e os volumes de figuras.

As regras do Regulamento de 1881 (PORTUGAL, 1881) eram muito menos detalhadas do que as de 1870 (PORTUGAL, 1870) e aparentemente estiveram em vigor até 1896. A partir dessa data, os conteúdos dos exames tornaram-se semelhantes aos dos cursos das escolas normais.

\section{Os exames de admissão às escolas normais}

A Reforma da Instrução Pública de 1844 (PORTUGAL, 1844) definiu pela primeira vez a habilitação necessária para a entrada em Escolas Normais, que, no entanto, nunca chegaram a funcionar:

[...] ter dezoito anos completos de idade; saber ler e escrever correntemente e a prática das quatro espécies de contas; possuir as primeiras noções de gramática portuguesa, e conhecimentos suficientes de religião do Estado; não padecer de moléstia contagiosa, ou outra que inabilite para o magistério; e ser reconhecidamente bem morigerado [bem-educado]. (PORTUGAL, 1844, p. 307). 
Em termos gerais, essa matriz continuou a ser seguida nas peças legislativas seguintes. Em 1860 foi publicado o novo Regulamento para a Escola Normal Primária do Distrito de Lisboa (PORTUGAL, 1860), que, como vimos, foi o primeiro a ser concretizado. Os candidatos apresentar-se-iam aos exames de admissão na Escola Normal, no distrito de Lisboa, e perante os Reitores dos liceus nacionais, no caso dos outros distritos. Esse conjunto de requisitos manteve-se no resto do período em análise.

Para além de servirem para graduar os candidatos, já que estavam em jogo bolsas de estudo que apoiavam o regime de internato, esses exames de acesso tinham como objetivo, entre outros, reconhecer se os candidatos sabiam ler e escrever corretamente, se conheciam os primeiros rudimentos de gramática portuguesa e a doutrina cristã (art. $35^{\circ}$ ). No âmbito da matemática, os candidatos faziam uma prova designada de Resolução de problemas do uso comum que dependam apenas da combinação das operações fundamentais da aritmética (art. $36^{\circ}$ ).

No que diz respeito à matemática, os exames de admissão do Regulamento de 1881 (PORTUGAL, 1881) compreendiam provas escritas e provas orais, similares aos de 1860. Apenas os temas de aritmética eram mais aprofundados, com o exame de propriedades das quatro operações.

O Regulamento Geral do Ensino Primário (PORTUGAL, 1896), aprovado em 1896, introduziu novas escolas complementares distritais, nas quais funcionavam cursos distritais de habilitação para o magistério primário que davam acesso à profissão. Quanto às Escolas Normais usuais (em Lisboa, Porto e Coimbra), esse Regulamento apenas mencionava exames para os alunos que pretendessem seguir o regime de internato com uma pensão estatal. Esses exames compreendiam provas escritas e orais que, quanto aos temas matemáticos, incidiam sobre a resolução de problemas de uso comum, prática das quatro operações em inteiros e decimais e prática do sistema de pesos e medidas.

A Reforma de 1901 (PORTUGAL, 1891) fixou pela primeira vez a obrigatoriedade de um diploma das escolas normais para o acesso à profissão de professor do ensino primário. O número máximo de alunos a admitir nas escolas seria fixado anualmente pelo governo, de acordo com as necessidades. Aos candidatos às escolas normais passava a ser exigida a aprovação no exame de instrução primária e em exame especial de admissão perante a respetiva escola. Os exames de acesso às escolas desse regime (PORTUGAL, de 1902) não eram muito diferentes dos anteriores. As provas escritas envolviam a resolução de um problema de aritmética e um de geometria (art. 206), que eram eliminatórias. As provas orais incidiam sobre os programas de instrução primária. 


\section{Disciplinas dos cursos das escolas normais}

Analisaremos seguidamente as disciplinas relacionadas com tópicos matemáticos que foram constituindo os cursos para a formação de professores do ensino primário. Como ponto prévio importa clarificar que o conceito de disciplina não teve um significado constante ao longo do período em análise. Na legislação encontramos por vezes denominações imprecisas sugerindo que a sua concretização ficava ao critério dos professores, por exemplo, Aritmética com a extensão possível, de 1845 (PORTUGAL, 1845). Encontramos ainda casos em que nem mesmo existe uma denominação plausível, por exemplo, Aritmética, noções de geometria elementar e suas aplicações mais usuais, escrituração comercial e indústria, de 1896, que se refere a um conjunto de tópicos e que quase constitui um programa per se. Exemplos idênticos podem ser encontrados noutros ramos do sistema de ensino português da época (ALMEIDA; MATOS, 2014).

A reforma de 1844 foi a primeira que apresentou uma estrutura curricular explicitando a duração e segmentando os cursos em disciplinas. Os estudos eram distribuídos por dois cursos, um de habilitação para as cadeiras do ensino primário do primeiro grau, com a duração de um ano, e o outro curso de dois anos, para as cadeiras do segundo grau. Se necessário, estes cursos podiam durar mais um ano. Para além da formação teórica, os alunos tinham também exercícios de prática de ensino numa escola primária. Os conteúdos de matemática estavam presentes em Desenho Linear e Aritmética e Geometria, que em 1845 se desdobrou em Aritmética na extensão possível e Geometria com Aplicação à Indústria.

O Regulamento da Escola Normal Primária do Distrito de Lisboa de 1860 teve uma importância acrescida, já que foi o primeiro a ser posto em prática em 1862. Seguindo a tradição anterior, os estudos foram distribuídos por dois cursos que correspondiam aos dois graus em que se dividia a instrução primária. O curso do $1^{\circ}$ grau durava dois anos e incluía a Aritmética, compreendendo as proporções e a sua aplicação aos usos da vida, sistema legal de pesos e medidas e Desenho linear e suas aplicações mais úteis na vida comum. O curso do segundo grau incluía ainda a Continuação do desenho linear, compreendendo as noções elementares de geometria e suas aplicações práticas e durava três anos. Não se detetam grandes diferenças no que se refere aos conteúdos matemáticos. As novidades limitavam-se à explicitação do sistema métrico, entretanto obrigatório no país (ALMEIDA e CANDEIAS, 2014), e à Pedagogia que aparece como disciplina autónoma no $1^{\circ}$ grau. A legislação de 1870 manteve a designação das disciplinas no curso do $1^{\circ}$ grau e no do $2^{\circ}$ grau, surgindo as Noções de 
geometria e suas aplicações práticas. A Pedagogia passou a incluir aspetos relacionados com a Metodologia, no segundo grau.

A legislação de 1881 era muito mais detalhada e estabelecia um curso de três anos onde se acrescentava o tema da álgebra à disciplina de Aritmética. Já o Regulamento Geral do Ensino Primário de 1896 (PORTUGAL, 1896) incluía a disciplina de Aritmética, noções de geometria elementar e suas aplicações mais usuais, escrituração comercial e industrial. A álgebra foi substituída pelas noções de contabilidade.

A legislação de 1901 incluía algumas apreciações sobre os conteúdos programáticos explicitando algumas críticas aos programas anteriores. O programa das escolas normais deve:

[...] ser suficientemente extenso, para que os professores, nelas habilitados, estejam à altura de bem desempenhar a profissão; mas não convém que o seja tanto que, em vez de ótimos mestres, dali saiam pedantes superficiais e pretensiosos. Melhor é dar, portanto, ao programa, em lugar de extensão exagerada, mais intensidade, organizando-o sempre de harmonia com as matérias do ensino primário. (PORTUGAL, 1901, p. 1232).

Assim, era acrescentado um ano ao curso e, por outro lado, eram reduzidos os programas de algumas disciplinas, nomeadamente da disciplina de ciências naturais, que se considerava ter um desenvolvimento desequilibrado relativamente às restantes disciplinas. Era também justificado o número de anos para a preparação do magistério, três anos, com o facto de não serem exigidas muitas habilitações aos candidatos. Dizia-se no texto legislativo que, se fossem exigidas maiores habilitações, provavelmente os dois anos de curso bastariam, mas assim, os três anos não seriam excessivos. Neste preâmbulo, apresentava-se o exemplo de alguns países que tinham cursos normalistas mais curtos, mas que exigiam à entrada a frequência e aproveitamento em cursos preparatórios, como na Prússia ou na Baviera. No caso de países em que não existiam esses preparatórios, os cursos normalistas eram mais longos, como na Suécia ou no Japão, onde duravam quatro anos. O curso de três anos era desta forma considerado suficiente para uma preparação adequada dos alunos para o exercício do magistério. Para essa preparação era também considerada indispensável a prática nas escolas anexas às escolas normais.

Nessa Reforma desapareceu a distinção entre curso para os professores do $1 .^{\circ}$ e do $2 .^{\circ}$ graus do ensino primário e logo em setembro do ano seguinte foi regulamentada a reforma da instrução primária de 1901 (PORTUGAL, 1902). Os temas matemáticos eram abordados em Aritmética prática e geometria elementar e Desenho linear e de ornato. As disciplinas com conteúdos matemáticos estavam 
presentes nos três anos do curso, sendo aquelas que apresentavam uma maior carga horária. Na disciplina de Pedagogia explicitava-se que incluía a Metodologia de ensino.

No quadro 1, resumimos as denominações das disciplinas que compreendiam conteúdos relacionados à matemática ou ao seu ensino, o que nos permite ter uma visão global da matemática escolar das escolas normais, no sentido de Chervel (1990).

Quadro 1 - Comparação entre as denominações das disciplinas relacionadas à matemática e o seu ensino nas escolas normais

\begin{tabular}{|c|c|c|c|}
\hline & Aritmética & Geometria & Pedagogia \\
\hline \multirow[t]{2}{*}{1844} & \multicolumn{2}{|c|}{ Aritmética e geometria com aplicação à indústria } & - \\
\hline & & Desenho linear & - \\
\hline 1845 & $\begin{array}{l}\text { Aritmética com a extensão } \\
\text { possível }\end{array}$ & $\begin{array}{l}\text { Desenho linear } \\
\text { Geometria com aplicação à } \\
\text { indústria }\end{array}$ & - \\
\hline 1860 & $\begin{array}{l}\text { Aritmética, compreendendo } \\
\text { as proporções e a sua } \\
\text { aplicação aos usos da vida, } \\
\text { sistema legal de pesos e } \\
\text { medidas }\end{array}$ & $\begin{array}{l}\text { Desenho linear e suas } \\
\text { aplicações mais úteis na vida } \\
\text { comum } \\
\text { Exercícios de aplicação da } \\
\text { geometria à agrimensura }\end{array}$ & $\begin{array}{l}\text { Pedagogia prática, } \\
\text { conhecimento da legislação } \\
\text { e administração do ensino }\end{array}$ \\
\hline 1870 & $\begin{array}{l}\text { Aritmética, compreendendo } \\
\text { as proporções e a sua } \\
\text { aplicação aos usos da vida, } \\
\text { sistema legal de pesos e } \\
\text { medidas }\end{array}$ & $\begin{array}{l}\text { Noções de geometria e suas } \\
\text { aplicações práticas } \\
\text { Desenho linear }\end{array}$ & $\begin{array}{l}\text { Pedagogia, conhecimento } \\
\text { da legislação do ensino } \\
\text { primário } \\
\text { Continuação da pedagogia } \\
\text { e metodologia }\end{array}$ \\
\hline 1881 & $\begin{array}{l}\text { Aritmética, sistema legal de } \\
\text { pesos e medidas, noções de } \\
\text { álgebra }\end{array}$ & $\begin{array}{l}\text { Geometria elementar e suas } \\
\text { aplicações mais usuais } \\
\text { Desenho }\end{array}$ & $\begin{array}{l}\text { Pedagogia e metodologia; } \\
\text { legislação relativa às } \\
\text { escolas primárias }\end{array}$ \\
\hline 1896 & \multicolumn{2}{|c|}{$\begin{array}{l}\text { Aritmética, noções de geometria elementar e suas aplicações } \\
\text { mais usuais, escrituração comercial e industrial }\end{array}$} & $\begin{array}{l}\text { Pedagogia; legislação } \\
\text { relativa às escolas } \\
\text { primárias }\end{array}$ \\
\hline 1901 & \multicolumn{2}{|c|}{$\begin{array}{l}\text { Aritmética prática e geometria elementar, noções de } \\
\text { escrituração comercial e agrícola }\end{array}$} & $\begin{array}{l}\text { Pedagogia, em especial } \\
\text { metodologia, legislação da } \\
\text { escola primária portuguesa }\end{array}$ \\
\hline
\end{tabular}

Fonte: PORTUGAL $(1844,1845,1860,1870,1881,1896,1901)$.

\section{Programas das disciplinas dos cursos das escolas normais ou de habilitação para o magistério primário}

O estudo dos programas permite-nos aprofundar as normas (JULIA, 1995) associadas à matemática nas escolas normais. Do que nos foi possível apurar, até 1881 a legislação para o ensino 
normal não incluiu descrições pormenorizadas dos conteúdos a lecionar. Em contraste, os programas publicados no Regulamento para a execução das leis sobre a instrução primária de 1881, os integrados no Regulamento Geral do ensino primário de 1896 (PORTUGAL, 1896), assim como os Programas para o ensino normal de 1902, continham uma descrição pormenorizada dos temas e conteúdos a lecionar em cada disciplina, o que nos permite analisar sucessivamente os diversos tópicos matemáticos. Essa mudança ocorre no contexto do início da difusão das ideias da Escola Nova em Portugal (MATOS, 2014).

\section{Números inteiros e respetivas operações}

O estudo do sistema de numeração decimal e das quatro operações aritméticas estava naturalmente presente nas escolas normais. Em relação a esse tema, no Regulamento para a execução das leis sobre a instrução primária (PORTUGAL, 1881), o programa do $1^{\mathrm{o}}$ ano da disciplina de Aritmética, sistema legal de pesos e medidas, noções de álgebra iniciava-se com noções preliminares de aritmética, na qual eram trabalhadas a numeração falada e escrita de números inteiros, as operações fundamentais sobre números inteiros e as provas dos nove para as quatro operações sobre inteiros, com a demonstração da sua ineficácia, com exemplos e exercícios práticos que deveriam ser feitos no quadro preto. No final de cada um desses tópicos eram recomendados exercícios. Os teoremas relativos às operações sobre números inteiros eram privilegiados no $2^{\circ}$ ano do curso, sendo as regras de divisibilidade privilegiadas no $1^{\circ}$ ano. Abordava-se a regra prática para encontrar o resto da divisão de qualquer número inteiro por 10, 100, 1000, assim como regras para encontrar o resto da divisão de qualquer número inteiro por 2, 3, 5, 9 e 11 e a prova dos onze sobre as quatro operações fundamentais. Para todos esses tópicos eram recomendados exercícios. No $2^{\circ}$ ano do curso, nas condições de divisibilidade dos números inteiros, era pedida a demonstração das condições de divisibilidade por 10, 2 ou 5, e por potências desses números, e ainda por 3, 9 ou 11. Trabalhava-se a teoria e a prática das provas. Também era proposta a resolução de exercícios.

Relativamente aos números primos, começava-se por estudar a regra prática para identificar se um determinado número é primo, não sendo, no entanto, identificada de que regra se tratava. Passavase depois à prática de decomposição de qualquer número inteiro positivo num produto de fatores primos.

Também era estudada a definição de máximo divisor comum e de números primos entre si, assim como um processo prático, que nos programas não era identificado, para encontrar o máximo 
divisor comum entre dois ou mais números inteiros. Seguia-se a definição de menor múltiplo comum de dois ou mais números inteiros e o processo de encontrar o menor múltiplo comum de dois ou mais números inteiros. Nesse tópico era ainda trabalhada a determinação do menor múltiplo comum e máximo divisor comum de dois ou mais números pela decomposição em fatores primos. No final de cada tópico havia sempre a recomendação para a realização de exercícios. No $2^{\circ}$ ano do curso recordavam-se os princípios fundamentais relacionados aos números primos, não sendo discriminados de que princípios se tratavam. Voltava-se a trabalhar a decomposição de um número em fatores primos e a formação dos divisores de um número inteiro. Eram também recordados os tópicos da teoria do máximo divisor comum e do menor múltiplo de dois ou mais números inteiros.

No Regulamento geral do ensino primário (PORTUGAL, 1896), o programa dos dois primeiros anos das Escolas Normais coincidia com o do ensino primário complementar. Nesse tema, o programa não exibia diferenças significativas em relação ao programa anterior. No entanto, os tópicos que em 1881 estavam distribuídos pelos três anos do curso, estavam em 1896 concentrados no $1^{\circ}$ ano.

Em 1902, foram aprovados novos Programas para o Ensino Normal, já previstos na reforma de 1901. Em geral, os programas eram semelhantes aos de 1896, embora fazendo uso de uma terminologia matemática mais elaborada. Era incluído o estudo da numeração romana e no $3^{\circ}$ ano o único tópico referente ao tema dos números inteiros era o cálculo de expressões aritméticas, que não existia anteriormente. O programa apresenta ainda sugestões de procedimentos didáticos. Por exemplo, no tópico dos números primos, os futuros professores deveriam reconhecer que a série dos números primos é ilimitada e o Crivo de Eratóstenes era referido explicitamente como método para encontrar números primos. Referia-se ainda a utilização de outras regras para saber se um número é primo, não sendo explicitadas quais seriam essas regras. Fazia-se a decomposição de um número em fatores primos e trabalhavam-se os números primos entre si, os divisores comuns de dois ou mais números e o maior divisor comum, sendo sugerido o processo das divisões sucessivas ou o processo da decomposição fatorial.

Esses programas possuíam uma terminologia que remete para processos matemáticos mais complexos do que os que o professor usaria nas suas aulas, referindo regras aritméticas gerais e solicitando a justificação de procedimentos. Nas operações com números inteiros, para além do seu conhecimento, era também pedido aos futuros professores que soubessem a sua definição, regras e teoria, estando implícito o conhecimento das propriedades fundamentais dessas operações. 


\section{Números fracionários e números decimais}

$\mathrm{Na}$ disciplina de Aritmética, sistema legal de pesos e medidas, noções de álgebra de 1881, o programa do $1^{\circ}$ ano iniciava-se com noções preliminares de aritmética onde eram também trabalhados

os números fracionários e decimais ${ }^{3}$ e as operações fundamentais sobre números decimais. Nesse $1^{\circ}$ ano era tratada a simplificação de quebrados, a redução ao mesmo denominador e a redução ao menor denominador comum. Nesse tema eram praticadas as quatro operações aritméticas sobre quebrados ${ }^{4}$. A redução de quebrados a dízima e a redução de números decimais a quebrados era o último tópico do tema. Em relação a estes tópicos, eram recomendados exercícios.

$\mathrm{O} 2^{\circ}$ ano dessa disciplina iniciava-se com teoremas relativos às operações sobre decimais e quebrados, para além dos inteiros, já tratados anteriormente. Em relação aos quebrados, era trabalhada a redução dos quebrados a dízima e o contrário, fazendo-se, também, a determinação do limite de qualquer dízima periódica, simples ou mista. Recomendava-se a resolução de exercícios.

Nesse tema, os programas de 1896 e de 1902, e tal como aconteceu com o tema dos números inteiros, são idênticos ao anterior, mas condensam os conteúdos apenas no $1^{\circ}$ ano do curso normal.

\section{Potenciação}

No Regulamento para a execução das leis sobre a instrução primária, de 1881, o estudo da potenciação começava no $1^{\circ}$ ano do curso, com a sua definição e o ensino da regra para a formação de qualquer potência de 10, 100, 1.000. Em seguida, eram apresentados diversos tópicos com regras de operações com potências, como a multiplicação de diversas potências da mesma raiz, multiplicação de potências do mesmo grau ${ }^{5}$, regra para achar qualquer potência de uma potência indicada, quociente de duas potências da mesma raiz ou do mesmo grau. No final de cada um desses tópicos eram recomendados exercícios.

Os dois últimos temas do $1^{\text {o }}$ ano dessa disciplina eram a raiz quadrada e a raiz cúbica. Relativamente à raiz quadrada, começava-se por fazer a sua definição, seguia-se o quadrado de números dígitos, a regra prática para encontrar a raiz quadrada de um número inteiro ou decimal e a regra prática para encontrar a raiz quadrada de um quebrado. No que diz respeito à raiz cúbica, também se iniciava com a sua definição, trabalhando-se depois o cubo dos números dígitos e a regra prática para achar a raiz cúbica de um número inteiro ou decimal. Relativamente a esses temas, também eram recomendados exercícios. 
No $2^{\circ}$ ano era trabalhada a multiplicação e a divisão de potências de inteiros e o $3^{\circ}$ ano começava com os logaritmos, tendo os alunos que aprender a teoria geral dos logaritmos deduzida a partir da comparação de duas progressões. Teriam ainda que conhecer as propriedades gerais e particulares dos logaritmos vulgares, a disposição e o uso das tábuas e, ainda, o complemento aritmético de um logaritmo.

Tal como acontecia nos dois temas anteriores, no Regulamento geral do ensino primário de 1896 este tema é tratado de forma semelhante ao de 1881. Nota-se, no entanto, alguma preocupação em recomendar abordagens didáticas a temas mais complexos. Por exemplo, é sugerido que o uso de logaritmos fosse aplicado à resolução de expressões fracionárias. O programa de 1902 é semelhante, embora o estudo das raízes quadradas fosse limitado apenas a números inteiros e o das raízes cúbicas tivesse sido retirado.

\section{Progressões e álgebra}

No $2^{\circ}$ ano dos programas de 1881 , eram apresentados tópicos relacionados com as proporções e progressões, onde se trabalhava inicialmente as proporções e progressões por diferença, teoremas sobre a inserção de meios aritméticos e soma de números em progressão aritmética. As proporções por quociente, com as divisões proporcionais, as progressões por quociente, os teoremas sobre a inserção de meios geométricos e a soma de números em progressão geométrica, eram outros dos tópicos. Por último, era discutida a noção de limite e limite da soma dos termos de uma progressão geométrica decrescente. Para todos esses tópicos eram recomendados exercícios.

O último tema do $2^{\circ}$ ano do curso normal designava-se, explicitamente, noções de álgebra. Era inicialmente abordado o uso das letras para a representação dos resultados, aplicando-se a problemas de juros, de desconto ou de divisão proporcional. Os futuros professores teriam que refletir sobre as vantagens das representações algébricas.

Ainda em relação a esse tema, no $3^{\circ}$ ano constavam as operações algébricas fundamentais, frações algébricas e ainda se fazia o estudo das quantidades negativas. No tema de álgebra eram ainda trabalhadas as diferentes espécies de igualdade, a avaliação do grau de uma equação, resolução de equações do $1^{\text {o }}$ grau a uma incógnita e equações simultâneas do $1^{\text {o }}$ grau. Trabalhava-se, ainda, os casos de indeterminação e impossibilidade e a teoria das desigualdades. Recomendava-se a resolução de exercícios e a resolução de problemas de uma equação do $1^{\circ}$ grau a uma incógnita. 
Nos programas de 1896 e de 1902, optou-se por eliminar a designação de noções de álgebra no nome da disciplina. Eliminaram-se também muitos dos conteúdos relacionados à álgebra, mantendo-se apenas o tema das progressões, não incluindo o estudo dos limites. Salienta-se que nesse último programa se optou por incluir o desenvolvimento do quadrado da soma e diferença de dois termos e o desenvolvimento da diferença dos quadrados de dois termos, sendo esses conteúdos apresentados no contexto da disciplina de aritmética, embora se tratem de conteúdos de álgebra.

\section{Cálculo comercial}

Conforme referimos anteriormente, esses programas incluíam tópicos relacionados à matemática, mas que têm claramente uma ligação a aplicações profissionais. Tal é o caso das noções de escrituração comercial que optámos por designar de cálculo comercial. No $1^{\circ}$ ano de 1881 , o cálculo comercial surgia como um dos temas onde era trabalhada a regra de três simples e composta. No final desse tema, recomendava-se a resolução de problemas variados e frequentes sobre essas regras.

No $2^{\circ}$ ano era abordada a regra conjunta, a regra de juros e suas espécies, a regra de compra e venda de fundos públicos, ações e obrigações de bancos e companhias, a regra de câmbio e a regra de companhia, de liga, de mistura ou de preço médio. Para além dos exercícios que eram recomendados em todos os tópicos, sugeria-se também a resolução de problemas sobre as regras indicadas, utilizando o sistema de redução à unidade e as proporções. No $3^{\circ}$ ano da disciplina não existiam referências ao cálculo comercial.

Em geral, os programas de 1896 e 1902 eram semelhantes ao de 1881. O de 1902 aprofundava temas contabilísticos específicos, como, por exemplo, diário, razão, caixa, inventários e balanço, ativo e passivo, e diversos sistemas de escrituração.

\section{Geometria e medida}

Nos programas analisados é difícil separar a geometria da medida. Esta secção opta por uma abordagem que se inicia com a medida, que nos programas analisados está, muitas vezes, integrada na aritmética, a que se segue a geometria, embora existam muitos pontos em comum. Nos conteúdos de geometria é ainda de salientar que junto dos conteúdos a lecionar eram feitas algumas recomendações no sentido dos conteúdos serem utilizados na resolução de problemas, que se poderiam considerar como indicações de caráter metodológico. 
Quanto à medida, no Regulamento para a execução das leis sobre a instrução primária de 1881 (PORTUGAL, 1881), esses tópicos estavam distribuídos entre as disciplinas de Aritmética, sistema legal de pesos e medidas, noções de álgebra, Geometria elementar e suas aplicações mais usuais e Desenho. Na disciplina de Aritmética, o segundo tema do $1^{\circ}$ ano era o sistema métrico decimal. Os alunos trabalhariam a noção do que é medir uma grandeza e a utilização de diferentes espécies de medida. Eram recomendados exercícios práticos. Logo a seguir era trabalhado o tema das medidas de comprimento, no qual os alunos deveriam estudar tópicos como os instrumentos e os diversos modos de medir, diferentes unidades adotadas para as distâncias itinerárias, a légua geográfica e a marítima e os seus valores em metros.

Os temas que se seguiam abordavam as medidas de superfície, de volume, de capacidade e de peso. Nas medidas de superfície eram estudadas as unidades, os múltiplos e submúltiplos e as medidas agrárias. Nas medidas de volume eram trabalhadas as unidades fundamentais, unidades derivadas, medidas para lenha e para madeira e formas práticas de as usar. Nas medidas de capacidade, os alunos aprendiam as formas, a sua construção a as utilizações mais frequentes. Nas medidas de peso trabalhavam a unidade principal e mais usual, a sua derivação e formas diferentes de medidas de peso. Era ainda trabalhado um tópico onde se estabelecia a relação entre as medidas de peso e as unidades de volume. No final de cada um desses temas eram recomendados exercícios.

Ainda no $1^{\circ}$ ano da disciplina de Aritmética era feita, inicialmente, a definição de número complexo e incomplexo. A redução de número incomplexo a outro e a redução de um número complexo à sua unidade da ínfima espécie, ou a qualquer outra, eram conteúdos ainda trabalhados nesse tópico. A redução de um número incomplexo a um número complexo e as quatro operações sobre números complexos eram os dois últimos tópicos desse tema. Os números complexos também eram um tema abordado no segundo ano do curso normal, onde era feita a redução de números incomplexos a outros incomplexos ou a números complexos e o contrário. Eram ainda trabalhadas as operações com números concretos, complexos ou incomplexos. Todos os tópicos tinham a recomendação da execução de exercícios.

Os programas de 1896 e de 1902 abordavam de forma semelhante o tema da medida, embora alguns temas (unidade de área, volume, capacidade e peso) tivessem passado para o âmbito da geometria. Nos diferentes programas analisados era sempre estudado o sistema monetário. Nesse tema abordava-se os metais usados nas moedas, o peso e as dimensões das moedas portuguesas, o título e a tolerância concedidos a estas medidas. 
O tema da geometria surgia em 1881 no programa de Geometria elementar e suas aplicações mais usuais. O primeiro tópico desse programa, designado de noções preliminares, referia-se à definição dos principais termos na geometria: linha reta, circunferência e círculo, arcos, ângulos, perpendiculares, oblíquas e paralelas e proporcionalidade das retas. No $2^{\circ}$ ano eram trabalhados mais temas geométricos: círculos que cortam retas, triângulos, quadriláteros, polígonos, perímetros e áreas das figuras planas, noções de agrimensura e prática com instrumentos.

No início do $3^{\circ}$ ano era dada a indicação de que deveriam ser apresentados problemas práticos sobre a avaliação de áreas, aos alunos da escola anexa à escola normal, tendo como referência o que tinham aprendido no sistema métrico decimal. No $3^{\circ}$ ano eram ainda trabalhados os seguintes tópicos: noções gerais de geometria no espaço; ângulos poliedros e triedros; definição das principais figuras no espaço; teoremas fundamentais sobre os poliedros; descrição e propriedades de superfícies cónicas, cilíndricas e esféricas; áreas de poliedros e de corpos limitados por superfícies curvas; volume de poliedros e de corpos terminados em superfícies curvas; comparação de volumes; cartonagem.

A geometria estava ainda presente na disciplina de Desenho do regulamento de 1881 . Nesse tema era trabalhada a representação das figuras geométricas. No $2^{\circ}$ ano do curso voltava-se a trabalhar o desenho geométrico, onde se recapitulavam as figuras estudadas no $1^{\circ}$ ano e se fazia a representação gráfica de todas as figuras abrangidas pelo programa de geometria plana. No $3^{\circ}$ ano do curso, o desenho geométrico abordava os poliedros e as suas definições e os exercícios sobre as diferentes perspetivas. Não existiam diferenças substanciais nesse tema entre o programa de 1881 e os de 1896 e de 1902.

\section{Metodologia}

Os programas analisados continham, a partir de 1881, a designação de Metodologia nas disciplinas que abordavam os aspetos pedagógicos. A introdução dessas disciplinas marca o desenvolvimento de um saber pedagógico específico para o ensino primário, que vai materializar nos manuais que então começam a ser produzidos e que nos permitem vislumbrar o seu desenvolvimento autónomo (CHERVEL, 1990). Como referimos, ela coincide com o desenvolvimento do ideário da Escola Nova e com a procura de uma fundamentação científica para os métodos educacionais (MATOS, 2014).

Embora os programas não contivessem indicações específicas para o ensino da matemática, essas disciplinas dividiam-se em Pedagogia, Metodologia geral e Metodologia especial. Na primeira, 
abordava-se a organização da escola e os métodos gerais de ensino e, na segunda, eram examinados os métodos de ensino dos diferentes ramos de instrução. É possível inferir que seria no âmbito desta disciplina que seriam abordados os métodos para o ensino dos conteúdos de matemática, que depois seriam praticados nas escolas anexas. Como consequência dessa nova organização curricular, vai-se gerar um novo conhecimento e novas práticas que vão recompor a cultura escolar, do ensino primário português, no sentido de Julia (1995). Uma compreensão mais aprofundada do que seria trabalhado nessa Metodologia especial, carece de uma análise de outras fontes, o que não está no âmbito deste artigo.

\section{Conclusões}

Traçámos um quadro dos saberes matemáticos e do seu ensino desenvolvidos nas escolas normais durante o período em análise. Embora limitados às normas, no sentido de Julia (1995), podemos desde já estabelecer algumas conclusões.

Comparando os conteúdos dos exames de acesso à profissão de professor para os candidatos que não tinham frequentado as escolas normais com os conteúdos exigidos aos alunos dessas escolas, é patente a maior exigência destes últimos, exigência mais significativa à medida que as escolas foram tornando mais elaborados os programas dos seus cursos. Uma sequência similar ocorre no gradual aumento dos requisitos para os candidatos às próprias escolas normais, que no início do período se limitavam a um conhecimento básico da leitura e da escrita e que em 1902, para além do diploma do ensino primário, já exigia um domínio sólido dos conhecimentos desse nível.

Quanto às disciplinas das escolas normais, dois eixos se tornaram claros. Se por um lado os conteúdos matemáticos foram se tornando mais complexos (incluindo, por exemplo, a álgebra ou os logaritmos), por outro desde muito cedo a matemática estudada contém uma componente prática e envolve temas próximos de aplicações profissionais (contabilidade, agrimensura), fazendo parte da função formativa das escolas primárias portuguesas no período em análise.

O desenvolvimento de saberes específicos para o ensino da matemática vai tornar-se evidente no período em análise, acompanhando a difusão das ideias da Escola Nova em Portugal. Por um lado, as disciplinas de pedagogia geral parecem gradualmente ir incluindo aspetos relacionados com métodos e processos específicos para o ensino das matérias a lecionar no ensino primário, onde se inclui os conteúdos de matemática, revelando a gradual elaboração de saberes específicos da profissão. A 
inclusão da designação de metodologia especial, nas disciplinas de pedagogia é um sinal revelador. Por outro lado, é patente a gradual inclusão de sugestões de caráter metodológico nos próprios programas das disciplinas relacionadas com os conteúdos de matemática, onde é comum a recomendação de resolução de exercícios ou de problemas.

\section{Notas}

${ }^{1}$ Neste texto optamos por utilizar o itálico no nome das disciplinas, mantendo a designação da época, mas com a ortografia atual.

${ }^{2}$ O Ensino Mútuo, método utilizado por Lancaster a partir do início do século XIX na Inglaterra e posteriormente divulgado em outros países, consiste na utilização de alunos mais avançados no ensino de colegas que sabem menos. Sobre o método e o desenvolvimento destas escolas, ver Gomes (1996) e, especialmente, Conde (2005).

${ }^{3}$ Nesse contexto, as frações decimais são partes da unidade sucessivamente menores umas que as outras, na razão de 10. Escrevem-se da mesma forma que os números inteiros, sendo colocados à direita destes.

${ }^{4}$ Os quebrados, ou frações ordinárias, representam-se por dois números, separados por um risco. O número por baixo, denominador, designa as partes em que a unidade se encontra dividida. $\mathrm{O}$ número de cima, numerador, de quantas dessas partes consta a quantidade representada. Têm esta designação para se diferenciarem das frações decimais. Quando o numerador é igual ao denominador, o quebrado vale uma unidade. Se vale mais do que unidade, tem o nome de quebrado impróprio.

${ }^{5}$ Atualmente ler-se-ia multiplicação de diversas potências da mesma base e multiplicação de potências do mesmo expoente.

\section{REFERÊNCIAS}

ALMEIDA, Mária; CANDEIAS, Rui. Os programas de matemática do ensino primário, da Telescola e do Ciclo Preparatório do Ensino Secundário. In: ALMEIDA, António J.; MATOS, José M. (Coord.), A matemática nos programas do ensino não-superior (1835-1974). Caparica: UIED; APM, 2014. p. 3968.

BARROSO, João. Políticas educativas e organização escolar. Lisboa: Universidade Aberta, 2005.

CANDEIAS, António (Coord.). Modernidade, educação e estatísticas na ibero-américa dos séculos XIX e XX. Lisboa: Educa História, 2005.

CARVALHO, Rómulo de. História do ensino em Portugal desde a fundação da nacionalidade até ao fim do regime de Salazar-Caetano. 2. ed. Lisboa: Gulbenkian, 1996.

CHERVEL, André. História das disciplinas escolares: reflexões sobre um campo de pesquisa. Teoria \& Educação, Porto Alegre, n. 2, p. 177-229, 1990.

CONDE, Maria Teresa. O modo de ensino mútuo na formação dos mestres de primeiras letras. Uma experiência pedagógica no Portugal oitocentista. Revista Lusófona de Educação, Lisboa, n. 6, p. 17137, 2005. 
GOMES, Joaquim Ferreira. Estudos para a história da educação no século XIX. Lisboa: Instituto de Inovação Educacional, 1996.

JULIA, Dominique. La culture scolaire comme objet historique. Paedagogica Historica, v. 1, p. 353$382,1995$.

MATOS, José Manuel. História do ensino da matemática em Portugal: a constituição de um campo de investigação. In: MATOS, José Manuel; VALENTE, Wagner Rodrigues (Ed.). A Matemática Moderna nas escola do Brasil e de Portugal: primeiros estudos. São Paulo: GHEMAT, 2007. p. 8-20.

MATOS, José Manuel. A matemática no ensino não-superior em Portugal. In: MATOS, José Manuel (Ed.). A matemática nos programas do ensino não-superior (1835-1974). Caparica: UIED; APM, 2014. p. 15-35.

MCCULLOCH, Gary. Documentary Research. Education, History and the Social Sciences, Londres, 2004.

NÓVOA, António (Org.). Profissão professor. Porto: Porto Editora, 2003.

PINTASSILGO, Joaquim (Coord.). Escolas de formação de professores em Portugal. Lisboa: Colibri, 2012.

PINTASSILGO, Joaquim; MOGARRO, Maria João. Das escolas normais às escolas do magistério primário: percurso histórico das escolas de formação de professores do ensino primário. Historia y Memoria de la Educación, Madrid, n. 1, p. 203-238, 2015.

PINTASSILGO, Joaquim; MOGARRO, Maria João; HENRIQUES, Raquel Pereira. A formação de professores em Portugal. Lisboa: Colibri, 2010.

PORTUGAL. Regulamento Geral da Instrução Primária. Coleção Oficial da Legislação Portuguesa, Lisboa, 1835. p. 309-313,

PORTUGAL. Reforma da Instrução Pública. Coleção Oficial da Legislação Portuguesa, Lisboa, 1844. p. 306-330.

PORTUGAL. Regulamento para a Escola Normal Primária do Distrito de Lisboa. Coleção Oficial da Legislação Portuguesa, Lisboa, 1845. p. 923-932.

PORTUGAL. Regulamento da Escola Normal Primária do Distrito de Lisboa. Coleção Oficial da Legislação Portuguesa, Lisboa, 1860. p. 814-821.

PORTUGAL. Regulamento para os exames dos concorrentes às cadeiras de ensino primário do $1^{\circ}$ e $2^{\circ}$ grau. Coleção Oficial da Legislação Portuguesa, Lisboa, 1869. p. 512-515. 
PORTUGAL. Programa para os exames dos concorrentes ao magistério primário no ano de 1870. Diário do Governo, Lisboa, n. 64, p. 1-2, 1870.

PORTUGAL. Regulamento para a execução de leis sobre a instrução primária. Coleção Oficial da Legislação Portuguesa, Lisboa, 1881. p. 145-191.

PORTUGAL. Regulamento geral do ensino primário. Coleção Oficial da Legislação Portuguesa, Lisboa, 1896. p. 474-516.

PORTUGAL. Decreto nº 8, de 1901. Reforma do ensino primário e do ensino normal. Coleção Oficial da Legislação Portuguesa, Lisboa, 1901. p. 1229-1246.

PORTUGAL. Decreto no 4. Regulamento do decreto no 8 de 24 de dezembro de 1901. Coleção Oficial da Legislação Portuguesa, Lisboa, 1902. p. 917-945. 


\section{Mathematics in the training of primary school teachers in Portugal, from Pombal reform from 1772 to 1910}

\begin{abstract}
Teacher training schools for elementary grades played a central role in shaping pedagogical knowledge in Portugal. So, this work aims to contribute to the understanding of mathematical knowledge and its teaching which were developed in these schools until 1910. This documentary historical study was based on legislation (laws, decrees, orders, circulars and instructions sent to schools) in which we looked for references to mathematics and its teaching. It is studied successively in the text, after a brief characterization of the evolution of normal schools, the presence of mathematics: in the entrance examinations for candidates without the normal schools' degree; in the entrance examinations to normal schools; in the disciplines of these schools; and in the content of these disciplines grouped according to the mathematical topics. As for the mathematical content, two axes have become clear. On the one hand they have become more complex (including for example algebra and logarithms) and on the other, since very early, the mathematics studied included themes for professional applications (accounting, surveying) that were part of the formative role of Portuguese primary schools in the period of analysis. As for the content of mathematics teaching, general pedagogy approaches seem gradually to include methods and processes specific to the teaching of mathematics revealing the gradual development of specific knowledge of the profession. The study of these programs shows the gradual construction of a set of mathematical knowledge, which go beyond what the future teacher would have to teach, and some methodological suggestions in line with what you would expect from a gradual
\end{abstract}

\section{Le mathématique dans la formation de maîtres des écoless primaires au Portugal, de la réforme du pombaline en 1772 jusqu'à 1910}

\section{Résumé}

Les écoles de formation des enseignants pour les années élémentaires ont joué un rôle central dans l'élaboration de la connaissance pédagogique au Portugal. Ce travail veut comprendre la connaissance mathématique et son enseignement développés dans ces écoles jusqu'à 1910. Cette étude historique documentaire est basée sur la législation (lois, décrets, arrêtés, circulaires et instructions destinés aux écoles). Le texte, après une brève caractérisation de l'évolution des écoles normales, étudie la présence des mathématiques successivement: dans les examens d'entrée à la profession pour les candidats sans le cours des écoles normales; dans les examens d'entrée dans les écoles normales; dans les disciplines de ces écoles; et dans le contenu des disciplines réunies selon les topiques mathématiques. Dans ce qui s'agit du contenu mathématique, deux axes sont devenus clairs: d'une part, ils sont devenus plus complexes (incluant, par exemple, l'algèbre et les logarithmes), d'autre part quelques topiques étudiés portent sur des questions provenant d'applications professionnelles (comptabilité, d'arpentage) et qui font partie du rôle de formation des écoles primaires portugaises dans le période analysé. L'étude de ces programmes montre la construction progressive d'un ensemble de connaissances mathématiques qui vont au-delà de ce que le futur enseignant aurait à enseigner, où sont aussi présentés quelques suggestions de façon méthodologique, en ligne avec ce que vous attendez d'un renforcement progressif d'une culture de l'école de formation des enseignants des premières anneés. 
construction of a school culture of primary teacher training.

Keywords: General history of education. Formation of educational professionals. Mathematics Education.
Mots-clés: Histoire générale de l'éducation. Formation des professionnels de l'éducation. L'enseignement des mathématiques.

\section{Rui Candeias}

E-mail: ruicandeias1@ sapo.pt

Recebido em: 25/5/2015

José Manuel Matos

Aprovado em: 27/11/2015

E-mail:jmm@fct.unl.pt 